\title{
Birth preparedness and complication readiness among rural women of reproductive age in Abeshige district, Guraghe zone, SNNPR, Ethiopia
}

This article was published in the following Dove Press journal:

International Journal of Women's Health

22 December 2016

Number of times this article has been viewed

\section{Kebebush Zepre' \\ Mirgissa $\mathrm{Kaba}^{2}$}

'Guraghe Zone Health Department, Wolkite, SNNPR, ${ }^{2}$ School of Public Health, Addis Ababa University, Addis Ababa, Ethiopia
Correspondence: Mirgissa Kaba School of Public Health, Addis Ababa University, PO Box 15182, Addis Ababa, Ethiopia

Email mirgissk@yahoo.com
Background: Birth preparedness and complication readiness (BPCR) is a strategy that helps women to consider all available maternal health care services during pregnancy and prepare for potential complications. Federal Ministry of Health in Ethiopia has taken steps to roll out the strategy at community level. Yet, women in rural communities still do not make use of available services to avoid complications in connection to pregnancy and delivery.

Objective: This study aims to assess the current BPCR practice and determine associated factors among rural women of reproductive age in Abeshige district, Guraghe zone, SNNPR, Ethiopia. Methods: A community-based cross-sectional study was carried out from February to March 2015. A total of 454 women were randomly selected and interviewed using pretested structured questionnaires, while opinion leaders, health extension workers, and selected women in the community were engaged in in-depth interviews and focus group discussions, using checklists prepared to guide the interviews. Data from different sources were analyzed, triangulated, and interpreted to respond to the objectives.

Results: Thirty-seven percent of the respondents were found to have prepared for birth and its complications. BPCR was higher among women who lived within a 1-hour walk from a health center (adjusted odds ratio $[\mathrm{AOR}]=3.51,95 \%$ confidence interval $[\mathrm{CI}]: 1.78,36.79$ ) and who were aware of the danger signs of pregnancy (AOR $=1.72,95 \% \mathrm{CI}: 1.78,2.94)$ and postpartum complications ( $\mathrm{AOR}=2.32,95 \% \mathrm{CI}: 1.32,4.21$ ). A major source of information was found to be health extension workers and one-to-five women networks ( $\mathrm{AOR}=2.81,95 \% \mathrm{CI}: 1.34,6.21$ ) and $(\mathrm{AOR}=2.52,95 \% \mathrm{CI}: 1.17,5.54)$, respectively. Qualitative finding revealed that lack of transportation and concern over cost of services are key barriers to BPCR.

Conclusion: BPCR in Abeshige was found to be relatively low, calling for more interventions beyond mere awareness. Availing transportation services and ensuring services free of charge would help in improving BPCR in the study area.

Keywords: maternal health, preparing for birth, community level care, safe pregnancy and delivery

\section{Introduction}

In the year 2013, approximately 287,000 maternal deaths occurred worldwide because of reasons associated with pregnancy and childbirth. Eighty-five percent of these deaths occurred in sub-Saharan Africa and South Asia. ${ }^{1}$ Major causes of such mortality were commonly attributed to failure to use available maternal health care services during pregnancy and failure to prepare for potential complications in connection to delivery. Use of available maternal health services and improvements in preparedness for potential problems during pregnancy and delivery would improve maternal health. 
The Government of Ethiopia has introduced a flagship Health Extension Program where young high school graduates were trained for 1 year on prevention of public health problems at village level (Federal Ministry of Health, unpublished data, 2005). These health extension workers (HEWs), among others, are expected to promote public awareness related to maternal health and available services and ensure that pregnant women attend antenatal care (ANC) services, deliver in health facilities assisted by skilled birth attendants, and receive postnatal care. ${ }^{2}$ A recent study has documented an improved care system for both mothers and newborns in connection to deployment of HEWs at community and household level., ${ }^{2,3}$ Yet, the mortality rate of mothers is still one of the highest in the world, and is only gradually declining. ${ }^{4}$ Recently, the mini-Ethiopian Demographic and Health Survey reported that $32 \%$ of pregnant women made four ANC visits during their pregnancy while $15 \%$ of women delivered at health facilities supported by skilled attendants. ${ }^{5}$ After years of endeavors to improve access to health services, this recent report ${ }^{5}$ illustrates the challenge posed in improving maternal health services.

Improved access to health facilities with maternal health services and improvement in availability of equipment, supplies, and skilled health care workers have been commonly documented to decrease maternal mortality. More importantly, birth preparedness and complication readiness (BPCR) is an important measure to improve utilization of maternal health services by planning for normal birth and predicting actions needed in case of emergency. It encourages women, family, and communities to make arrangements such as identifying a skilled health care provider, place of delivery, and transport to place of delivery, setting aside money to pay for service fees and transport, and organizing a blood donor in order to reduce delays in accessing care if a problem arises. ${ }^{6}$

Although there are not many studies on BPCR in Ethiopia, the few available studies conducted in Gondar, Sidama, and Arba Minch show that awareness on BPCR is limited. These studies mentioned several danger signs in connection to pregnancy, delivery, and postpartum complications..$^{7-9}$ There are other studies that have documented that $<20 \%$ of women practice BPCR. ${ }^{10-13}$ The studies unanimously reported that educated women and those who reside in urban settings are relatively more aware of BPCR and tend to make necessary preparations to make use of available maternal health services. Although there are documented challenges in making BPCR popular among all pregnant women, there is a dearth of evidence on what proportion of women are aware of and practice BPCR in a rural setup.

Thus, this study was designed to assess current BPCR practice and associated factors in the rural Guraghe zone of the
Southern Regional State of Ethiopia. Findings from this study are expected help planners, administrators, and stakeholders in the field of maternal health to modify BPCR strategy, thereby, on one hand, improving maternal health service utilization, and decreasing maternal mortality on the other. It will also generate additional research questions for future study.

\section{Methods}

\section{Study area and period}

The study was conducted in the Abeshige district, Gurage zone of SNNPR from February to March 2015. Abeshige is one of the 15 districts in the Guraghe zone. The district is located $185 \mathrm{~km}$ southwest of Addis Ababa. It has two urban and 26 rural kebeles. The population of Abeshige district is estimated at 76,610 , of which the female population is $51 \%$. According to data from the district health office, there were 17,926 women of reproductive age, of whom 2,528 were reported to have delivered within 12 months preceding the survey. In the district, there are four health centers (three governments and one nongovernmental organization), two urban and 26 rural health posts, twelve private clinics, one drug store, and one rural drug vendor. All the health centers and health posts provide maternal health services. According to a 2013 report from the district health office, ANC and institutional delivery were found to be $97 \%$ and $21 \%$, respectively (Abeshige woreda Health Office, unpublished data, 2013).

\section{Study design and study population}

A community-based, cross-sectional survey, supplemented by a qualitative study, was carried out in the Abeshige district of Gurage zone in SNNPR. All women of reproductive age who delivered within 12 months prior to the study (irrespective of place of delivery and birth outcome), who were permanent residents in the district, and who volunteered to participate in the study were considered as study participants. Yet, those women who were severely sick (not in connection to pregnancy or delivery) were excluded from the study.

\section{Sample size determination}

The sample size was calculated using a single population proportion formula, following such assumptions as $95 \%$ confidence level, $5 \%$ margin of error between the sample and the population, $16 \%$ proportion of women who practice BPCR in reference to a previous study in one of the regions in Ethiopia, ${ }^{10}$ $10 \%$ nonresponse rate, and $2 \%$ design effect. Accordingly, 454 women were included as study participants.

\section{Sampling technique}

All rural kebeles of the district were grouped into four clusters (Hole, Mamede, Walga, and Darge) in accordance with the 
distribution of four health centers. As there was no social, economic, or climatic variation between the clusters, one cluster was randomly selected for this study. All the eight kebeles in the selected cluster were included in the study. The number of participants from the respective kebeles was proportionally determined on the basis of their respective population size (women who delivered within 12 months prior to this survey). At the kebele level, a systematic random sampling technique was employed. Following random selection of the first household with a woman who fulfilled the selection criteria, subsequent households with women meeting the criteria were selected from every eighth house until the desired sample size was reached in each kebele. For households with more than one eligible woman, one of the women was chosen using a lottery method.

Participants in the qualitative study included mothers who were not involved in the survey, husbands, HEWs, and traditional birth attendants who were identified on the basis of their knowledge regarding women's health and/or had a specific role in efforts to improve maternal health in the community.

\section{Data collection tools and procedure}

A pretested structured and semistructured questionnaire was used to collect information. The questionnaire was adapted from monitoring BPCR tools for maternal and newborn health. ${ }^{5}$ The questionnaire was translated into Amharic and back-translated to English to ensure consistency. The questionnaire was designed to measure sociodemographic characteristics, obstetric history, awareness of obstetric complication danger signs and practice of BPCR, and personal and social factors influencing the practice of BPCR. Six diploma nurses who were recruited from health facilities out of the study area were trained to collect data. Data collection was closely supervised by health professionals who were recruited from other health facilities. At the end of every day, completeness of data was checked, and any incomplete questionnaire was returned to data collectors, based on ID number, for completion. A 2-day training was given to both data collectors and supervisors to discuss the aim of the study, data collection methods, ethical issues, and procedures. This was complemented with practical roleplays and field exercises.

An open-ended checklist with probes was used to collect evidence on local understanding of barriers to BPCR. Four focus group discussions (FGD) sessions (with a total of 32 male and female participants of equal size) and eight in-depth interviews were completed by the principal investigator who was supported by an assistant who recorded the information.

\section{Measurement}

A woman was considered as aware of key danger signs of pregnancy complications if she spontaneously mentioned at least two of the three key danger signs (vaginal bleeding, swollen hands/face, and blurred vision). A woman was considered as aware of key danger signs of labor/childbirth complications if she spontaneously mentioned at least three of the four key danger (vaginal bleeding, prolonged labor [ $>12$ hours], convulsions, and retained placenta). A woman was considered as aware of key danger signs of postpartum complications if she spontaneously mentioned at least two of the three key danger signs (vaginal bleeding, foul smelling vaginal discharge, and high fever). A woman was considered as prepared for birth and its complications if she had made arrangements for at least three of the BPCR component practices (identified place of delivery, identified skilled health care provider, saved money, identified transport ahead of emergency, and identified blood donor) by translating BPCR practices into a single outcome variable. Midwives, doctors, and nurses who were trained with skills necessary to diagnose and manage normal births, and manage or refer obstetric complications, were considered as skilled attendants.

\section{Data analysis}

Survey data were first checked manually for completeness and were coded following a template prepared for this purpose. Data were entered into Epi-Info 3.5.3 statistical software, cleaned, and transferred to SPSS version 21 for analysis. Descriptive analysis was made and presented using frequency tables and percentage. Bivariate analysis was made to determine the association between BPCR and such variables as sociodemographic, awareness, and role of Health Extension workers using odds ratio. These predictors with significant association were further tested using multivariate logistic regression at $P \leq 0.05$ and $95 \%$ confidence interval (CI). Qualitative data were transcribed into English text, read and reread and sorted into themes following the research questions. Accordingly, raw data were categorized under following sections: what is known about BPCR, sources of support to deliver in health facility, and what needs to improve in the future.

Different steps were followed to ensure data quality. During the training, trainees were equipped with the objectives and relevance of the study, and role played on how to do interviews and record. As part of the training, study tools were pretested in one of the kebeles with similar characteristics but fairly far from the selected study cluster, and the study tools were revised on the basis of the pretest. These pretest results were further discussed with data collectors and supervisors to consolidate better understanding of the tools and data 
collection process. During data collection, supervisors and the principal investigator checked completeness and took timely correction. At data entry, data were entered and cleaned using Epi-Info before exporting to SPSS for analysis.

\section{Ethical approval}

Written ethical clearance was obtained from the Research and Ethical committee of the School of Public Health, Addis Ababa University. A formal letter was written to the Abeshige district health office from the School of Public Health. On the basis of this, permission was obtained from the district health office and each kebele administration to conduct the study. Written informed consent was sought and obtained from every participant who agreed to take part in the study. They were assured about the confidentiality of their responses.

\section{Results}

\section{Sociodemographic characteristics of} the study population

A total of 449 women out of 454 , who gave birth within 12 months prior to this study, participated, making a response rate of $98.9 \%$. Age of participants ranged from 17 to 44 years with a mean of $29 \pm 6$ years. The majority (60.4\%) of the respondents were found to be 25-34 years of age, while 101 $(22.5 \%)$ were $35-44$ years of age. More than half $(57.2 \%)$ of the respondents were Muslims, while Orthodox and Protestants made up 191 (42.6\%) and 1 (0.2\%), respectively (Table 1).

The majority $(96.6 \%)$ of the respondents were found to be currently married, while the remaining proportion were separated, divorced, widowed, or single. Out of the total respondents, $378(84.2 \%)$ belong to Guraghe ethnic group, while the remaining were Amhara, Kebena, or Oromo. Regarding their educational status, about $250(55.7 \%)$ reported as not able to read and write, $167(37.2 \%)$ had primary education (grades $1-8), 17(3.7 \%)$ had secondary education, and approximately $15(3.4 \%)$ had informal education (Table 1).

Occupational characteristics of respondents showed that more than half $(53.9 \%)$ were housewives, followed by merchants (98 [21.8\%]), and farmers (90 [21.4\%]). The mean family size was $5.5 \pm 1.6$ standard deviation (SD) with a range of $2-10$ people in a household. About $43.4 \%$ of the women reported to live within a 30 - to 60 -minute walk from the health center, while a $30.3 \%$ resided more than 1 hour away from the health center (Table 1).

\section{Obstetric history of the respondent}

Sixty-one $(13.6 \%)$ of the respondents were primigravida, while $158(35.2 \%)$ of them had had five or more pregnancies.
Table I Sociodemographic characteristics of women of reproductive age group, Abeshige district, January $2015(\mathrm{n}=454)$

\begin{tabular}{ll}
\hline Variables & $\mathbf{N}(\%)$ \\
\hline Age (years) & \\
I7-24 & $77(17.1)$ \\
$25-34$ & $271(60.4)$ \\
$35-44$ & $101(22.5)$ \\
Religion & \\
Muslim & $257(57.2)$ \\
Orthodox & $191(42.6)$ \\
Protestant & $1(0.2)$ \\
Marital status & \\
Married & $434(96.7)$ \\
Separated & $6(1.3)$ \\
Divorced & $3(0.7)$ \\
Widowed & $1(0.2)$ \\
Single & $5(1.1)$ \\
Ethnicity & \\
Guraghe & $378(84.2)$ \\
Amhara & $26(5.8)$ \\
Kebena & $26(5.8)$ \\
Oromo & $19(4.2)$ \\
Educational status & \\
Illiterate & $250(55.7)$ \\
Read and write (informal) & $15(3.4)$ \\
Primary education (I-8) & $167(37.2)$ \\
Secondary and above & $17(3.7)$ \\
Occupational status & \\
Housewife & $242(53.9)$ \\
Merchant & $98(21.8)$ \\
Farmer & $96(21.4)$ \\
Daily laborer & $7(1.6)$ \\
Employee & $4(0.9)$ \\
Student & $2(0.4)$ \\
Family size & \\
I-3 & $53(11.8)$ \\
4-6 & $266(59.2)$ \\
Time it takes to travel from home to health center & $130(29.0)$ \\
in minutes/hour & \\
\hline 30-60 min & \\
\hline
\end{tabular}

Among the respondents, more than half (52.3\%) were found to have 2-4 children, while the proportion of respondents who had $\geq 5$ children was 148 (33\%). Mean gravidity and parity were found to be $3.8 \pm 1.9$ and 3.6 $\pm 1.9 \mathrm{SD}$, respectively. More than one-third $(34.1 \%)$ of women became pregnant for the first time below the age of 25 years, while 296 (65.9\%) of the respondents became pregnant for the first time at the age of 25-34 years. Forty ( $8.9 \%$ ) of the respondents had history of abortion, while 15 (3.3\%) of them had history of stillbirth.

\section{Maternal health service utilization}

Almost all (99.3\%) participants reported to have at least one ANC visit during their recent pregnancy. Among those who 
attended ANC, more than three quarters (78.4\%) attended four or more visits, while three $(0.7 \%)$ had made only one visit. The majority $(87.5 \%)$ of them attended their first ANC between 4 and 6 months of their pregnancy and $46(10.2 \%)$ attended their first ANC before 3 months of their pregnancy. Three hundred and thirty-two (73.9\%) mothers were supported on their ANC attendance by a skilled health care provider, while $114(25.4 \%)$ of them received ANC service from a HEW. Four hundred and twenty-two (94\%) respondents gave birth at health institutions supported by skilled health care providers, whereas 27 (6\%) of respondents gave birth at home. Among the participants, $153(34.1 \%)$ reported to have delivered in a health facility and $15(3.3 \%)$ of the respondents delivered via Cesarean section. Those who delivered in health facilities provided multiple reasons as to why they delivered in health facilities. Accordingly, it was found that interest to get professional service (381 [89.6\%]), instruction to deliver at health facility (267 [59.5\%]), previous positive experience delivering at health facility (128 [30.1\%]), previous negative outcome delivering at home (40 [9.4\%]), and access to health facility (96 [22.6\%]) were found as major reasons for delivering in a health facility. On the other hand, those who delivered at home reported short and smooth labors (23 [85\%]) and inaccessibility of health facility (14 [51.8\%]) as the major reasons for decisions to deliver at home.

\section{Awareness of danger signs of obstetric complications}

Ninety percent of the participants reported that they were informed about danger signs related to pregnancy complications. Among these, 328 (73.1\%), 139 (31.0\%), and $97(21.6 \%)$ women spontaneously mentioned vaginal bleeding, swollen hands/face, and blurred vision as danger signs during pregnancy. Besides this, one-third (34.9\%) of the respondents spontaneously mentioned at least two danger signs of pregnancy complications.

The qualitative findings substantiated that vaginal bleeding is the most common danger sign associated with pregnancy. Besides this, twin pregnancy and death of baby in the womb were identified as danger signs in connection to pregnancy. One of the respondents explained:

As I said, a woman is in a dangerous condition when she is pregnant of twins. As you all know [referring to discussants], three years back my neighbor delivered twin baby at home. The first one was born alive but the second one was born dead. After two weeks the mother herself died which shows the danger posed by twin pregnancy. [FGD participants, woman, 25 years old]
Unlike women, men (husbands) were found to be naïve about danger signs associated with pregnancy. One of the men who participated in the study highlighted what was agreed to by other male members who participated in the study:

I do not know much about these complications. However, I think abdominal pain and prolonged pregnancy beyond nine months are the main danger signs. [FGD participant, husband, 35 years old]

The majority of the respondents $(91.5 \%)$ reported to be informed about danger signs during labor and delivery. Among those who had information, 333 (74.2\%), 131 (29.3\%), 121 (26.9\%), and 65 (15.4\%) of the respondents spontaneously mentioned vaginal bleeding, retained placenta, prolonged labor, and convulsions, respectively, as danger signs associated with labor/delivery (Table 2). On the other hand, 103 (22.9\%) of the respondents spontaneously mentioned at least three of the key danger signs associated with labor/delivery.

The qualitative findings ascertained that vaginal bleeding, malpresentation, and retained placenta are common danger signs in connection to labor and delivery. An FGD participant pointed out that:

If there is vaginal bleeding at any time during pregnancy, if feet or hand of the fetus comes first during labor and placenta remains inside after delivery, the mother is considered to be in a dangerous condition and she may even die. [Woman, 27 years old]

Another in-depth interview participant pointed out:

When I was working as a local birth attendant in this community, if I encounter women during labor and if her labor takes longer than half a day, I escort her to health center since this considered dangerous for the life of a woman as well as the fetus. [In-depth interviewee, Traditional Birth Attendant, 49 years old]

Three hundred and ninety-nine $(88.8 \%)$ of the research participants reported that they were informed about danger signs during postpartum. Three hundred and twenty $(71.3 \%)$, $96(21.4 \%)$, and 37 (8.2\%) of the respondents spontaneously mentioned severe vaginal bleeding, high fever, and foul smelling vaginal discharge, respectively, as danger signs associated with the postpartum period. In addition, 90 (20.3\%) respondents spontaneously mentioned at least two of the danger signs of postpartum mentioned earlier (Table 2).

\section{Source of information about BPCR}

The vast majority of respondents $(95.8 \%)$ reported to have been informed about BPCR. Multiple responses revealed that 
Table 2 Awareness of obstetric danger signs among women of reproductive age group, Abeshige Woreda, January 2015 ( $N=454)$

\begin{tabular}{|c|c|c|c|}
\hline Variables & Spontaneous response & Category & Frequency (\%) \\
\hline \multirow[t]{6}{*}{ Danger signs of pregnancy complications } & Severe vaginal bleeding & Yes & $328(73.1)$ \\
\hline & & No & $121(26.9)$ \\
\hline & Swollen hand/face & Yes & $139(31.0)$ \\
\hline & & No & $310(69.0)$ \\
\hline & Blurred vision & Yes & $97(21.6)$ \\
\hline & & No & $352(78.4)$ \\
\hline \multirow[t]{8}{*}{ Danger signs of labor/delivery complications } & Severe vaginal bleeding & Yes & $333(74.2)$ \\
\hline & & No & $116(25.8)$ \\
\hline & Prolonged labor $\geq 12$ hours & Yes & $12 \mid(26.9)$ \\
\hline & & No & $328(73.1)$ \\
\hline & Convulsion & Yes & $69(15.4)$ \\
\hline & & No & $380(84.6)$ \\
\hline & Retained placenta & Yes & |3| (29.2) \\
\hline & & No & $318(70.8)$ \\
\hline \multirow[t]{6}{*}{ Danger signs of postpartum complications } & Severe vaginal bleeding & Yes & $320(71.3)$ \\
\hline & & No & $129(28.7)$ \\
\hline & Foul smelling vaginal discharge & Yes & $37(8.2)$ \\
\hline & & No & $412(91.8)$ \\
\hline & High fever & Yes & $96(21.4)$ \\
\hline & & No & $353(78.6)$ \\
\hline \multirow[t]{6}{*}{ Awareness of obstetric danger signs during: } & Pregnancy & Yes & $157(34.9)$ \\
\hline & & No & $292(65.1)$ \\
\hline & Labor/delivery & Yes & $106(23.6)$ \\
\hline & & No & $343(76.4)$ \\
\hline & Postpartum & Yes & $90(20.3)$ \\
\hline & & No & $359(79.7)$ \\
\hline
\end{tabular}

HEW (372 [82.9\%]), health workers at the health facility level (222 [49.4\%]), information shared through radio (98 [21.8\%]), one-to-five women networks at the village level (44 [9.8\%]), and conferences of pregnant mothers (16 [3.6\%]) were major sources of information about BPCR.

The qualitative findings showed that health workers, including HEWs and community-level discussions, are important sources of information about BPCR. One of the participants contended that:

When I attended ANC, the provider informed me to deliver in health facility. To that effect, I was encouraged to stay at or around the health facility so as to avoid possible delays to come to health facility during labor. Since my home is far away, rushing to health facility when labor occurs is difficult. Such information, which is provided to all pregnant women is very important. [In-depth interviewee, woman, 28 years old]

One of the HEWs has also commented that:

Currently our (HEW) role among others is to create awareness about maternal health service utilization and encourage women to take necessary precautions during pregnancy, delivery and postpartum. Guided by family manual, I provide specific information on obstetric danger signs to all of my clients. In my catchment, every mother plans for birth during pregnancy to deliver at health facility. [In-depth interviewee, HEW, 35 years old]

\section{Preparations for birth and complications}

In planning for pregnancy, delivery, and postpartum, women were found to be supported by relatives such as mothers and mother-in-laws. It was found that the majority (92.7\%) and $356(79.3 \%)$ of the respondents reported to obtain support from husbands and relatives, respectively. Such planning was found to encompass dedicating money for transport, arrangements for who should accompany the woman when she travels to the health facility, and taking care of children who remain at home while she is at the health facility. A relatively small proportion $(8.7 \%)$ of respondents reported making the decision to seek health care in relation to their pregnancy, labor, and postpartum by their own, while 403 (89.8\%) made the decision jointly with their husbands.

Preparations for birth and associated complications were found to be pervasive. Preparations of food items and clothing for the newborn were identified as major preparations by 442 $(98.4 \%)$ of the respondents. Among the very important components of BPCR, 427 (95.1\%) spontaneously mentioned the decision on place of delivery as the major component of preparation. Of those who mentioned place of delivery, 425 (99.5\%) planned to deliver in a health institution supported by a skilled health care provider, while the remaining proportion opted to deliver at home. To this effect, 296 (65.9\%) saved money, $225(50.1 \%)$ identified a skilled provider to help, and 213 $(47.4 \%)$ determined the mode of transportation, while 
35 (7.8\%) went further in identifying a blood donor in case there was the requirement. It was thus found that $37.2 \%$ of respondents were prepared for birth and its complications by making arrangements for at least three of these mentioned components of BPCR practices (Table 3). Of the 33 participants who experienced obstetric complications during their recent delivery, $75.8 \%$ were referred to a higher-level health facility for advanced services to manage their complications.

The qualitative findings have revealed that community members were well informed about the advantages of BPCR. HEWs and health professionals at the health facility level supported to improve community awareness about maternal health in general and BPCR in particular. In addition to efforts made to avail information, previous pregnancy- and delivery-related experiences were reported to play pivotal roles in understanding the value of BPCR. One of the FGD participants explained that:

In early days as close as five years, several mothers were buried with their pregnancy. Thanks be to Allah, today such problem is not as bad. Health extension workers as well as health workers at facility level consistently teach us as well as our women on preparations that women should do. In fact our previous experience has also helped us to draw lessons. To date, community members loan money for health related emergency from local edir's (self-help association) reserve, carry women to health facility if there is no transportation using what is commonly called local ambulance (local bed carrier). [FGD participant, husband, 38 years old]

A HEW strengthens the above idea by explaining that each development team in her kebele is expected to ensure the availability of the local ambulance (bed carrier) for emergency transport. Traditional birth attendants pointed out that:

Currently, a woman who delivers at home is punished 500 birr while one who assists such home delivery will be fined 300 birr. This, I think is one of the reasons for widespread preference to deliver in health center. [In-depth interviewee, TBA, 49 years old]

\section{Factors affecting BPCR}

Bivariate analysis shows that the mother's educational status, distance from a health center, awareness of danger signs, sources of information, and occupation were found to have a strong association with BPCR. The finding shows that literate mothers, women who live within a 1-hour walk from a health center, and women who have awareness of the danger signs of obstetric complications and danger signs of postpartum complications were more likely to take precautionary measures and prepare ahead of time. It was also found that the source of information about BPCR was

Table 3 Factors influencing practice of BPCR adjusted for confounding variables, in Abeshige district, January 20I5 ( $\mathrm{n}=454$ )

\begin{tabular}{|c|c|c|c|c|}
\hline \multirow[t]{2}{*}{ Variables } & \multicolumn{2}{|c|}{ Practice of BPCR } & \multirow[t]{2}{*}{ COR $(95 \% \mathrm{Cl})$} & \multirow[t]{2}{*}{ AOR (95\% Cl) } \\
\hline & Yes (\%) & No (\%) & & \\
\hline \multicolumn{5}{|l|}{ Education } \\
\hline Literate & $92(46.2)$ & $107(53.8)$ & $2.01(1.36,2.95)$ & $1.20(0.75,1.91)$ \\
\hline Illiterate & $75(30.0)$ & $175(70.0)$ & 1.00 & 1.00 \\
\hline \multicolumn{5}{|c|}{ Support from relatives } \\
\hline Yes & I 45 (40.7) & $211(59.3)$ & $2.22(1.31,3.74)^{*}$ & $\mathrm{I} .64(0.89,3.0 \mathrm{I})$ \\
\hline No & $22(23.7)$ & $71(76.3)$ & 1.00 & 1.00 \\
\hline \multicolumn{5}{|c|}{ Access to health center } \\
\hline$<\mathrm{I}$ hour & 118 (37.7) & $195(62.3)$ & $4.73(2.00,38.05)^{*}$ & $3.5 \mathrm{I}(1.78,36.79)^{*}$ \\
\hline$>1$ hour & $49(36.0)$ & $87(64.0)$ & 1.00 & 1.00 \\
\hline \multicolumn{5}{|c|}{ Awareness of danger signs of pregnancy complications } \\
\hline Yes & $85(54.1)$ & $72(45.9)$ & $3.02(2.02,4.53)^{*}$ & $1.75(1.04,2.94)^{*}$ \\
\hline No & $82(28.1)$ & $210(71.9)$ & 1.00 & 1.00 \\
\hline \multicolumn{5}{|c|}{ Awareness of danger signs of postpartum complications } \\
\hline Yes & $58(63.7)$ & $33(36.3)$ & $4.01(2.48,6.5 \mathrm{I})$ & $2.35(\mathrm{I} .3 \mathrm{I}, 4.2 \mathrm{I})^{*}$ \\
\hline No & $109(30.4)$ & $249(69.6)$ & 1.00 & 1.00 \\
\hline \multicolumn{5}{|c|}{ Source of information } \\
\hline \multicolumn{5}{|c|}{ Health extension worker } \\
\hline Yes & $154(4 \mid .4)$ & $218(58.6)$ & $2.69(1.26,5.72)^{*}$ & $2.89(1.34,6.21)^{*}$ \\
\hline No & $10(17.2)$ & $48(82.8)$ & 1.00 & 1.00 \\
\hline \multicolumn{5}{|c|}{ One-to-five women network } \\
\hline Yes & $30(68.2)$ & $14(3 \mid .8)$ & $3.21(1.54,6.66)^{*}$ & $2.52(1.17,5.39)^{*}$ \\
\hline No & $134(34.7)$ & $252(65.3)$ & 1.00 & 1.00 \\
\hline
\end{tabular}

Note: *Statistically significant.

Abbreviations: AOR, adjusted odds ratio; BPCR, birth preparedness and complication readiness; COR, crude odds ratio; $\mathrm{Cl}$, confidence interval. 
significantly associated with the practice of BPCR. Women who got information about BPCR from HEWs were more likely to prepare for birth and its complications as compared with those who got information from one-to-five networks and relatives (Table 3). Despite such evidence of predictors of BPCR following bivariate analysis, multivariate logistic regression revealed that the time taken to reach a health facility, women's awareness about obstetric complication danger signs, and source of information have a significant association with BPCR.

Accordingly, women who lived within a 1-hour walk from a health center were 3.5 times more likely to prepare for birth and its complications than those women who resided farther away (adjusted odds ratio [AOR] =3.51 [1.78, 36.79]). Mothers who were aware of danger signs of pregnancy and postpartum complications were two times more likely to prepare for birth and its complications than mothers who were not aware of danger signs of pregnancy $(\mathrm{AOR}=1.75,95 \% \mathrm{CI}$ : $1.04,2.94)$ and postpartum complications (AOR $=2.35,95 \%$ CI: $1.31,4.21)$. Women who got information about BPCR from a HEW were almost three times $(\mathrm{AOR}=2.89,95 \% \mathrm{CI}$ $=1.34,6.21)$ and those who received information from a oneto-five network were 2.5 times $(\mathrm{AOR}=2.52,95 \% \mathrm{CI}=1.17$, 5.39) more likely to prepare for birth and its complications compared with women who had not got information about BPCR from a HEW and/or one-to-five women networks, respectively (Table 3 ).

The qualitative findings have further explained barriers to prepare for birth and its complications. An in-depth interview participant explained that:

Even if a woman has planned to go to health facility at the onset of labor, immediate access to transportation is difficult. Although ambulance is available, usually it is not functional and getting private vehicle is unthinkable. In such situation, a woman should be carried on bed to the health center. [FGD participant, woman, 43 years old]

An FGD participant has also explained that:

Transport is the main obstacle for women to get to health facility when labor starts irrespective of prior plan. Last year, we brought a woman in labor to health center using local ambulance (Bed carrier). When we reach there, they referred her to Woliso hospital and we were requested to pay three hundred birr for fuel. Unfortunately, we were not prepared for that. [FGD, husband, 33 years old]

At times, even if a family saves money for pregnancy, delivery, and postpartum complications, it may have been spent for other purposes and not available when needed. Under such circumstances, a local saving scheme "edir" provides money on loan. Processing this may often take time. This was elaborated by one of the participants:

If husband or the person in charge of the money is not around to process the loan from "edir", it is difficult to take laboring women to health facility. [In-depth interviewee, woman, 38 years old]

Participants also reported that a husband's negligence is a barrier for timely action in connection to labor. One of the women pointed out that:

During my recent labor, I told him [husband] that I have pain which probably is labor and asked him to be around. Yet, he went away to the farm promising he will be back quickly. However, he stayed longer and, I delivered at home later in the afternoon before he returns back. [In-depth interviewee, woman, 30 years old]

However, it was found that this is not usual.

\section{Discussion}

Findings from this study revealed that nearly a quarter of the respondents were aware of most danger signs in connection to pregnancy, labor/delivery, and postpartum. It was found that HEWs and one-to-five networks of women were the major sources of information. Furthermore, the findings reveal that $37.2 \%$ of the respondents were prepared for birth and its complications by identifying a health facility for delivery, identifying means of transportation, and saving money for associated expense. It was evident that preparations of food items and clothing for the newborn are common practice among almost all women (98.4\%), while identification of potential blood donors in case of emergency was found to be critical preparation for at least $7.8 \%$ of the participants.

However, the findings are consistent with the studies from other settings. A study from Tsegedie district of Tigray region documented that $59 \%$ and $62 \%$ of respondents were aware of danger signs related to pregnancy and delivery complications, respectively. ${ }^{14}$ Another study from Sidama ${ }^{9}$ has documented that $30 \%, 41 \%$, and $37 \%$ of the respondents were aware of at least two danger signs in connection to pregnancy, delivery, and postpartum, respectively. Compared with the findings from the other settings, the level of awareness in our study setting of danger signs is relatively lower. Especially given this study is contemporary as compared to the two other studies,,${ }^{9} 14$ and given extensive interventions were running in Ethiopia to improve maternal health outcomes, relatively low 
levels of awareness from this study flags concern regarding the quality and level of intervention.

Findings on the practice of BPCR show that $22 \%$ of women participants from Tigray, ${ }^{15} 16.5 \%$ from Robe, ${ }^{11}$ $23.3 \%$ from Jimma, ${ }^{16}$ 17\% from SNNPR, ${ }^{12}$ 68.6\% from Addis Ababa, ${ }^{17}$ and $30 \%$ from Goba ${ }^{18}$ were found to have made BPCR plans. Our findings on BPCR, however, showed that $37.2 \%$ of the women who participated in the study made BPCR plans. This finding is far higher as compared with the studies from rural settings, although the findings from the study in Addis $\mathrm{Ababa}^{17}$ are understandably much higher. The difference with findings from rural settings may have to do with the difference in the study time and advantages of improved service delivery. The qualitative findings in the current study revealed that, generally, people are aware of the danger signs and what actions to take. It is also important to recognize the extensive community mobilization through HEWs and one-to-five networks, particularly focusing on encouraging women to deliver in health facilities. This may explain the relatively higher practice of BPCR compared with the previous reports, although this is not satisfactory in view of expectations.

The current study has documented that $95.1 \%$ of research participants identified place of delivery, which is important to obtain services of a skilled provider at a health facility-level institution. Among those who identified place of delivery, $425(99.5 \%)$ planned to deliver at the nearest health facility, implying that the overwhelming majority prefer to deliver in health facilities. This finding is quite high as compared to other studies. ${ }^{14-20}$ This could be explained by the fact that in recent years, there has been an extensive campaign to ensure maternal health service utilization, and women in Abeshige district have benefited from this. Yet, it should also be noted that as the study is cross-sectional in design, the findings may not provide strong evidence of underlying contexts beyond the study time. It is difficult to ascertain if those who planned to deliver at a facility would indeed do so.

To reach the place of delivery, plans were made to set aside money for necessary expenses, and on how to organize transport. Although saving money appears to be common in preparation for birth as revealed from studies from Tanzania $(89 \%)^{19}$ and Uganda $(91 \%),{ }^{20}$ findings from this study $(65.9 \%)$ and from Adigrat $(68.9 \%)^{15}$ revealed that saving money as part of BPCR is relatively limited, which may have to do with socioeconomic differences and the fact that, in Abeshige in particular, people live from hand to mouth and they may not have money to set aside in preparation for delivery.
Arranging transport ahead of time reduces the delay in seeking and reaching services. A study report from Uganda showed that $61 \%$ of pregnant women organized transportation well ahead of their due date. ${ }^{20}$ In this study, almost half (47.4\%) of the respondents organized transportation mechanisms ahead of scheduled due date, which is higher compared to studies done by Adigrat (24.7\%), ${ }^{15}$ Robe (28.5\%), ${ }^{11}$ and Jimma $(3.2 \%) .{ }^{10}$ This may have to do with the fact that there are different transportation options and relatively better road networks in the community. As was demonstrated in the qualitative findings, the community has an established practice of using the local ambulance (bed carrier) that is available at each got (village) for emergency purposes, to carry laboring woman to the main road where transport can be caught.

Of all components of BPCR, identification of a blood donor was found to be relatively neglected $(7.8 \%$ of the respondents reported to have identified blood donor in case of emergency, while the wider majority did not). This finding is consistent with the previous study from Ethiopia and another study from Tanzania. ${ }^{15,19}$

Access to a health center was found to have statistically significant association with BPCR practice. Women who lived within a 1-hour walk from a health center were 3.5 times more likely to prepare for birth and its complications than women who resided farther away from the health center. This finding was consistent with the studies on the same themes from Tanzania and Uganda. ${ }^{19,20}$ This witnesses the fact that distance to health facility is an important indicator for improved access to service.

Similarly, awareness of danger signs of obstetric complications was significantly associated with BPCR. Women who are aware of danger signs of pregnancy are more likely to prepare for birth and its complications compared to those who are not aware. The reason may have to do with the fact that mothers who are aware about obstetric complications may, consequently, fear problems. As found from the qualitative evidence, HEWs and one-to-five networks of women are the major sources of information on BPCR. This suggests that community-level structures are playing important roles in promoting awareness on improvement of women's health service utilization. Thus, strengthening such structures and capacities of providers at this level may improve BPCR uptake, thereby improving maternal health.

\section{Strength}

To the best of the authors' knowledge, to date, this is the most comprehensive study of its kind in Guraghe zone. Also, the fact that the study has used a mixed-method approach make 
the findings stronger. As such, the results could be used for BPCR in the Abeshige district.

\section{Limitation}

As with any cross-sectional study, the findings of the current study may not provide strong evidence on the direct cause-andeffect relationship between BPCR practice and explanatory variables. As the study focused on one district, the result may not be conclusive to the region at large. Also, some of the participants in the survey were interviewed 1 year after delivery, and therefore, some recall bias may have affected the findings.

\section{Conclusion and recommendation}

As part of BPCR, plans to deliver in a health facility in this district is found to be very high. However, overall BPCR practice was found to be low in the Abeshige district. Comprehensive community mobilization through HEWs and the one-to-five networks is believed to have played important role. Nonetheless, this has not been translated into improved uptake of BPCR and resultant outcomes. In a country where maternal mortality remains a major concern, investment in BPCR in its entirety is critical. From the findings, it appears that almost every pregnant woman prefers to deliver in a health facility. However, overall awareness is found to be limited. This suggests that perhaps the one-to-five networks may have been instructing women to deliver in health facilities instead of convincing them of the usefulness of such a practice. This may affect sustainability of the initiative in the district. Although not unique to this particular study, it was evident that saving money, planning transportation, and identifying a blood donor in case of emergency are other areas in need of improvement. Although building on the already established social mobilization and awareness creation structure at the community level, where HEWs and the one-to-five networks are playing pivotal roles, it is critical to build their capacity on mobilization and awareness creation. That would help sustained uptake of BPCR.

\section{Acknowledgments}

We extend our deepest gratitude to those who participated in the study for their time to provide relevant information. We wish to extend our thanks to data collectors and supervisors. Finally, we are grateful to IFHP/JSI and Wolkite University for the financial support they provided.

\section{Author contributions}

All authors contributed toward data analysis, drafting and revising the paper and agree to be accountable for all aspects of the work.

\section{Disclosure}

The authors report no conflicts of interest in this work.

\section{References}

1. The World Health Organization, United Nations Children's Fund, United Nations Fund for Population, The World Bank. Trends in maternal mortality: 1999-2013. Estimates by WHO, UNICEF, UNFPA, The World Bank and the United Nations Population Division; 2014: Geneva, Switzerland. Available from: https://openknowledge.worldbank.org/ bitstream/handle/10986/18203/879050PUB0Tren00Box385214B00P UBLIC0.pdf?sequence=1. Accessed November 21, 2016.

2. Merge K, Frances T, Ashebir G, Ali K, Mary C, Solomon T. Responding to the maternal health care challenge: the Ethiopian Health Extension Program. Ethiop J Health Dev. 2010;24(Special Issue 1): 105-109.

3. Karim AM, Admassu K, Schellenberg J, et al. Effect of Ethiopia's Health Extension Program on maternal and newborn health care practices in 101 rural districts: a dose-response study. PLoS One. 2013; 8(6): 65160.

4. National Planning Commission and the United Nations. Assessment of Ethiopia's Progress Towards the MDGs. National Planning Commission and the United Nations: Addis Ababa, Ethiopia; 2015.

5. Central Statistics Agency. Mini-Ethiopian Demographic and Health Survey Report. Central Statistics Agency: Addis Ababa; 2014.

6. JHPIEGO: Maternal and Neonatal Health. Monitoring birth preparedness and complication readiness tools and indicators for MNH. Johns Hopkins Bloomberg, School of Public Health Center for Communication Programs Family Care International; 2004: Baltimore, MA, USA. Available from: http://pdf.usaid.gov/pdf_docs/Pnada619.pdf. Accessed November 21, 2016.

7. Worku AG, Yalew AW, Afework MF. Maternal complications and women's behavior in seeking care from skilled providers in North Gondar, Ethiopia. PLoS One. 2013;8(3):e60171.

8. Workineh Y, Hailu D, Gultie T, et al. Knowledge of obstetric danger signs and its associated factors in Arba Minch Town, Ethiopia. Am J Health Res. 2014;2(5):255-259.

9. Mesay Hailu, Abebe Gebremariam, Fessahaye Alemseged. Knowledge about obstetric danger signs among pregnant women in Aleta Wondo district, Sidama zone, Southern Ethiopia. Ethiop J Health Sci. 2010;20(1): 25-32.

10. Debelew GT, Afework MF, Yalew AW. Factors affecting birth preparedness and complication readiness in Jimma zone, Southwest Ethiopia: a multilevel analysis. Pan Afr Med J. 2014;19:272.

11. Kaso M, Addisse M. Birth preparedness and complication readiness in Robe Woreda, Arsi zone, Oromia region, central Ethiopia: a crosssectional study. Reprod Health. 2014;11:55.

12. Markos D, Bogale D. Birth preparedness and complication readiness among women of child bearing age group in Goba woreda, Oromia region, Ethiopia. BMC Pregnancy Childbirth. 2014;14:282.

13. Hailu M, Gebremariam A, Alemseged F, Deribe K. Birth preparedness and complication readiness among pregnant women in Southern Ethiopia. PLoS One. 2011;6(6):e21432.

14. Hailu D, Berhe H. Knowledge about obstetric danger signs and associated factors among mothers in Tsegedie district, Tigray region, Ethiopia, 2013: community based cross-sectional study. PLoS One. 2014;9(2): e83459.

15. Mihret $\mathrm{H}$, Mesganaw F. Birth preparedness and complication readiness among women in Adigrat town, north Ethiopia. Ethiop J Health Dev. 2008;22(1):14-20.

16. Tura G, Afework MF, Yalew AW. The effect of birth preparedness and complication readiness on skilled care use: a prospective follow-up study in Southwest Ethiopia. Reprod Health. 2014;11:60.

17. Araya Luchia: Assessment of Knowledge and Practice on Birth Preparedness and Complication Readiness Among Antenatal Clients in Selected Health Centers in Addis Ababa, Ethiopia [master's thesis]; 2011. 
18. Bogale Daniel, Markos Desalegn. Institutional delivery service utilization and associated factors among child bearing age women in Goba Woreda, Ethiopia. J Gynecol Obstet. 2014;2(4):63-70.

19. Urassa DP, Pembe AB, Maganga F. Birth preparedness and complication readiness among women in Mpwapwa district, Tanzania. Tanzan $J$ Health Res. 2012;14(1).
20. Kabakyenga JK, Östergren PO, Turyakira E, Pettersson KO. Knowledge of obstetric danger signs and birth preparedness practices among women in rural Uganda. Reprod Health. 2011;8:33.

International Journal of Women's Health

\section{Publish your work in this journal}

The International Journal of Women's Health is an international, peerreviewed open-access journal publishing original research, reports, editorials, reviews and commentaries on all aspects of women's healthcare including gynecology, obstetrics, and breast cancer. The manuscript management system is completely online and includes a very quick and fair peer-review system, which is all easy to use. Visit http://www.dovepress.com/testimonials.php to read real quotes from published authors.

Submit your manuscript here: http://www.dovepress.com/international-journal-of-womens-health-journal 